Original Article

\title{
NOVEL FINDINGS OF PHOENIX DACTYLIFERA, DATES FRUIT EARLY-STAGE HABABUK FOR PHYTOCHEMICAL SCREENING, ANTIOXIDANT AND CYTOTOXIC POTENTIALS
}

\author{
SHAKKEELA YUSUF ERATTIL AHAMMED*, AREEJ MUHAMMED ALMUTAIRI, FATIMA SULIMAN AL-RASHIDI, \\ OHOUD FAHAD ALMUTAIRI
}

Department of Pharmaceutical Chemistry, Unaizah College of Pharmacy, Qassim University, Kingdom of Saudi Arabia, PO BoX 5888

Unaizah, 51911

*Email: s.ahammed@qu.edu.sa

Received: 20 Aug 2020, Revised and Accepted: 09 Mar 2021

\section{ABSTRACT}

Objective: The present study aims to investigate the phytochemical constituents, antioxidant, and cytotoxic activity of the total ethanolic extract of the hababuk stage of date's fruits Phoenix dactylifera (PDHE).

Methods: Extracts PDHE obtained with shade dried and a powdered sample of hababuk stage of date fruits Phoenix dactylifera and subjected to phytochemical screening, in vitro antioxidant activity study by DPPH assay and ABTS assay, in vitro cytotoxic studies carried out for three different cell lines Lung Cancer (A549), Human cervical carcinoma (HeLa) and Breast Cancer (MCF)-7 cells by MTT method and brine shrimp lethality assay using standard procedure.

Results: The phytochemical study revealed the presence of important constituents like alkaloids, glycosides, phenolic, flavonoids, carbohydrate, proteins, amino acids, terpenoids, steroids, and saponins. The antioxidant studies of the PDHE compared with standard showed very excellent results IC50 values for DPPH activity and nitric oxide. A good result was also shown by ABTS when compared with that of standard. The brine shrimp lethality assay is considered a useful tool for preliminary assessment of toxicity. The extract showed excellent LC ${ }_{50}$ value, which correlates with cytotoxicity studies previously established. The MTT study results using the three different cell lines compared with the standard doxorubicin, promising results obtained for HeLa cell lines when compared with other cell lines.

Conclusion: Results obtained from the present work indicated that the hebabuk stage of date fruit is a promoising antioxidant and anticancer agent Further study should be carried out to isolate the bioactive compound responsible for the activity.

Keywords: Date fruit, Ethanolic extract, Antioxidant, Hababuk, Brine shrimp, Phytochemical screening.

(C) 2021 The Authors. Published by Innovare Academic Sciences Pvt Ltd. This is an open access article under the CC BY license (https://creativecommons.org/licenses/by/4.0/) DOI: https://dx.doi.org/10.22159/ijpps.2021v13i5.39469. Journal homepage: https://innovareacademics.in/journals/index.php/ijpps.

\section{INTRODUCTION}

The potential medicinal properties of plant species have contributed significantly to the advance of abundant herbal therapies for a numeral of ailments across the world. The benefits of herbal medicine over allopathic medicine have aided medicinal plants to regain their reputation in the field of health and medicine [1]. The growth of awareness to cure diseases continued at an accelerating pace and some new plant-derived drugs increased likewise [2]. Medicinal plants are the richest bioresource of drugs in the traditional system of medicine also function as medicaments. These medicinal values of plants lie in some chemically active substance that produces a definite physiological action on the human body. Phytochemicals are biologically active and function to protect against disease and infection. Phytochemicals are broken into different classes, which include flavonoids, carotenoids, chlorophyll, and isothiocyanates [3]. Dates, Phoenix dactylifera, fruits historically important types of palm trees because they are a source of food that has supplied nutrition to millions of people over thousands of years. The plant and its various parts were evaluated for several pharmacological studies and found to have medicinal importance. Palm date fruits Phoenix dactylifera has been used for nutritional and medicinal purposes in Middle Eastern countries and is used in folk medicine for the treatment of liver diseases and highly recommended to be consumed by pregnant women before and after delivery [4].

The dates are believed to have many medicinal properties for example, to provide strength, fitness, and relief against many diseases and pains, including fever, stomach disorders, memory disturbances, nervous disorders, as well as an aphrodisiac and to boost immunity [5]. Nearly 400 different varieties of dates are available from Saudi Arabia, but only a limited number of date varieties have been utilized for scientific purposes [6]. Dates are of religious importance for Muslims throughout the world and it is mentioned in many places in the Holy Quran. Dates are very rich in phenolics, in quality and quantity, which opens many fields of investigation in terms of new potential uses. The presence of several reports on the chemical composition and the nutritional value of dates, many other potentialities of the fruits remain to be explored. Many claims report on the antibacterial, antifungal, antitumor antiulcer, and immunomodulatory properties of dates are reported [7]. Even more medicinal plants are available in the kingdom of Saudi Arabia, Date palm has its own powerful and unique importance. Knowing the useful nutrient and sources of food that should be beneficial for human mankind, we think of doing our research work in this plant. During our survey for the study, we came to know that work has been carried out in fruits, seed, and Dates pollen [8]. Hababuk stage, development of a small green colour fruit after a week of pollination was chosen for our research work and no study has been carried out in this stage before.

\section{MATERIALS AND METHODS}

\section{Sampling}

The date's fruits, Phoenix dactylifera early-stage hababuk were collected during April 2019 from Unaizah near Buraidah in Al Qassim region, Saudi Arabia. The Sample drug has been identified and authenticated from the College of Food and Agricultural Sciences, King Saud University, Riyadh, Saudi Arabia. The voucher specimen number PD17569 was deposited in the department.

\section{Chemicals and reagents}

ABTS, 2,2-diphenyl-1-picrylhydrazyl, Sodium nitroprusside, Griess reagent from (Sigma chemicals), Dulbecco's modified Eagles medium, Dimethyl sulphoxide, DMEM (Sigma Aldrich).), the 
antibiotic solution containing: Penicillin $(100 \mathrm{U} / \mathrm{ml})$, Streptomycin, and Amphotericin B from NBS Eppendorf, India, MTT kit from Roche, India, Sodium bicarbonate, potassium persulfate and Lglutamine from Merck India Ltd and HiMedia.

\section{Extraction}

Shade dried and powdered drug of Phoenix dactylifera, fruit earlystage hababuk was soaked in $95 \%$ ethanol in a round bottom flask and after soaking it for one day, it was refluxed for $3 \mathrm{~h}$ and the clear solution will be decanted off. The extraction was repeated thrice, the combined extracts were concentrated to a semisolid consistency. Thus, total ethanolic extract (TEE) was be obtained and designated as PDHE (Phoenix dactylifera hababuk extract) [9].

\section{Qualitative chemical test}

Various chemical tests were carried out for the PDHE to identify the presence of various phytochemical constituents. Chemical tests for phenolic (Ferric chloride test and Lead acetate test), chemical tests for flavonoids (Aqueous sodium hydroxide test and Shinoda test) and chemical test for carbohydrate (Fehling's Test, Molisch's Test, Benedict's Test, Tollen's test and Iodine test) [10].

\section{Antioxidant activity studies}

2,2-diphenyl-1-picrylhydrazyl (DPPH) assay was carried as explained before [11]. Concisely, a $3 \mathrm{ml}$ solution of DPPH $(0.1 \mathrm{mmol})$ and $2 \mathrm{ml}$ extract and standard ascorbic acid of each concentration were mixed and incubated in the dark for $30 \mathrm{~min}$ at room temperature. The absorbance of samples, standard, and blank (ethanol instead of DPPH) was measured at $517 \mathrm{~nm}$. The equation given below was used to calculate DPPH radical scavenging activity and linear regression analysis of absorbance against concentration was done to compute $\mathrm{EC}_{50}$ (representing $50 \%$ reduction) for $\mathrm{DPPH}$ value.

$$
\text { Percentage Inhibition }=\frac{\text { Absorbance of Blank }- \text { Absorbance of Sample }}{\text { Absorbance of blank }} \times 100
$$

The ABTS radical scavenging activity in PDHE was performed according to the method already reported [12]. In this assay, green ABTS+is generated under appropriate oxidant and was blocked in the presence of antioxidants $1.75 \mathrm{ml}$ of potassium persulfate $(2.45 \mathrm{mmol})$ with $100 \mathrm{ml}$ of ABTS $(7 \mathrm{mmol})$ in the ratio of $625: 11(\mathrm{~V} / \mathrm{V})$ were used to prepare $\mathrm{ABTS}^{+}$stock solution. Working solutions were prepared by diluting the stock solution with $0.05 \mathrm{M}$ phosphate buffer ( $\mathrm{pH} 7.4$ ) till the absorbance was read at $734 \mathrm{~nm}$. Different concentrations of extract and standard working solutions of 1:19 (V/V), were combined at room temperature and stored for $10 \mathrm{~min}$ in dark. Absorbance at taken $734 \mathrm{~nm}$ for $30 \mathrm{~min}$ against ethanol using Infinite M200 PRO microplate reader. The percentage ABTS radical scavenging activity (\%) was calculated using the equation given. Linear regression analysis was done to compute $\mathrm{EC}_{50}$ expressed as $\mu \mathrm{g} / \mathrm{ml}$. All the samples and standards were assayed in triplicates and averaged.

ABTS radical scavenging activity

$$
=\frac{\text { (Average OD of Control }- \text { Average OD of Test) }}{\text { Average OD of Control }} \mathrm{X} 100
$$

The concentration of the extract required to scavenge $50 \%$ of the radicals was calculated by plotting a graph of \% inhibition vs concentration [13].

Nitric oxide scavenging assay carried out for PDHE using sodium nitroprusside in aqueous solution at physiological $\mathrm{pH}$ spontaneously generates nitric oxide, which interacts with oxygen to produce nitrite ions, which can be measured at $546 \mathrm{~nm}$ spectrophotometrically in the presence of Griess reagent (1\% sulphanilamide, 2\% Phosphoric acid and $0.1 \% \mathrm{~N}$-(1-naphthyl) ethylenediamine dihydrochloride) which convert nitrite into the deep purple azo compound. The scavengers of nitric oxide reduce the production of nitric oxide [14]. All the samples and standard were assayed in triplicates and averaged.

$$
\text { Percentage inhibition }=\frac{\text { Control }- \text { Test }}{\text { Control }} \times 100
$$

\section{Acute cytotoxic by brine shrimp lethality assay}

Brine shrimps (Artemia salina) were hatched using brine shrimp eggs in a conically shaped vessel (1L), filled with sterile artificial seawater under constant aeration for $48 \mathrm{~h}$. After hatching, active nauplii free from eggshells were collected from the brighter portion of the hatching chamber and used for the assay. Ten nauplii were drawn through a glass capillary and placed in each vial containing $4.5 \mathrm{ml}$ of brine solution. In each experiment, $0.5 \mathrm{ml}$ of the extract was added to $4.5 \mathrm{ml}$ of brine solution and maintained at room temperature for $24 \mathrm{~h}$ under the light and surviving larvae were counted with a hand lens. Experiments were conducted along with control (vehicle-treated), different concentrations $(100-1000 \mu \mathrm{g} / \mathrm{ml}$ ) of the substances in a set of three tubes per dose. Based on the percent mortality, the $\mathrm{LD}_{50}$ of the test compound was determined using the probit scale[15].

\section{Antiproliferative by MTT assay}

MTT is a colorimetric assay that measures the reduction of yellow 3(4, 5-dimethythiazol-2-yl)-2,5-diphenyl tetrazolium bromide (MTT) by mitochondrial succinate dehydrogenase. The MTT enters the cells and passes into the mitochondria where it is reduced to an insoluble, colored (dark purple) formazan product. The cells are then solubilized with an organic solvent (isopropanol) and the released; solubilized formazan reagent is measured spectrophotometrically. Optical density will be read at $540 \mathrm{~nm}$ using DMSO as blank.

All the cell lines A549 (lung cancer), HeLa (cervical cancer), and MCF-7 (Breast cancer) cell lines were initially procured from National Centre for Cell Sciences (NCCS), Pune, India, and maintained in Dulbecco's modified Eagles medium, DMEM. The cell line was cultured in $25 \mathrm{~cm}^{2}$ tissue culture flask with DMEM supplemented with $10 \%$ FBS, L-glutamine, sodium bicarbonate, and the antibiotic solution containing: Penicillin $(100 \mathrm{U} / \mathrm{ml})$, Streptomycin $(100 \mu \mathrm{g} / \mathrm{ml})$, and Amphotericin B $(2.5 \mu \mathrm{g} / \mathrm{ml})$. Cultured cell lines were kept at $37{ }^{\circ} \mathrm{C}$ in a humidified $5 \% \mathrm{CO}_{2}$ incubator. Two days old confluent monolayer of cells were trypsinized and the cells were suspended in a $10 \%$ growth medium, $100 \mu \mathrm{l}$ cell suspension ( $5 \times 103$ cells/well) was seeded in 96 well tissue culture plate. $1 \mathrm{mg}$ of sample was weighed and dissolved in $1 \mathrm{ml}$ DMEM using a cyclomixer. The sample PDHE solution was filtered through a 0.22 $\mu \mathrm{m}$ Millipore syringe filter to ensure sterility. After $24 \mathrm{~h}$ the growth medium was removed, freshly prepared each compound in DMEM were five times serially diluted by two-fold dilution $(100 \mu \mathrm{g}, 50 \mu \mathrm{g}$, $25 \mu \mathrm{g}, 12.5 \mu \mathrm{g}, 6.25 \mu \mathrm{g}$ in $500 \mu \mathrm{l}$ of DMEM) and each concentration of $100 \mu \mathrm{l}$ was added in triplicates to the respective wells and incubated at $37^{\circ} \mathrm{C}$ in a humidified $5 \% \mathrm{CO}_{2}$ incubator. Non treated control cells were also maintained.

The entire plate was observed after $24 \mathrm{~h}$ of treatment in an inverted phase-contrast tissue culture microscope (Olympus CKX41 with Optika Pro5 CCD camera) and microscopic observation was recorded as images. Any detectable changes in the morphology of the cells, such as rounding or shrinking of cells, granulation, and vacuolization in the cytoplasm of the cells were considered as indicators of cytotoxicity.

After the incubation period, the supernatant was removed and $100 \mu \mathrm{l}$ of MTT solubilization Solution (Dimethyl sulphoxide, DMSO) was added and the wells were mixed gently by pipetting up and down to solubilize the formazan crystals. The absorbance values were measured by using a microplate reader at a wavelength of $540 \mathrm{~nm}$ [16]. The percentage of growth inhibition was calculated using the formula:

$$
\text { Percentage of viability }=\frac{\text { Mean OD samples }}{\text { Mean OD of the control }} \times 100
$$

\section{Statistical analysis}

Data were presented as mean \pm Standard Deviation for triplicates. For detailed information on data set and to gain insight into the distribution of phytochemicals and their bioactivities. The IC ${ }_{50}$ values for all the extracts were determined by ED 50 PLUS V1.0 Software [17].

\section{RESULTS AND DISCUSSION}

\section{Preliminary phytochemical evaluation}

The Preliminary phytochemical evaluation of the PDHE showed the presence of alkaloids, glycosides, phenolics, flavonoids, 
carbohydrates, proteins, amino acids, terpenoids, steroids, and saponins. The results of each chemical tests are recorded and tabulated in the following table 1 . The phytochemicals present in the PDHE justified the results obtained for antioxidant and cytotoxicity evaluation. The antioxidant activity studies like DPPH, ABTS, and Nitric oxide were carried for the ethanolic extract of Phoenix dactylifera hababuk extract, PDHE. Acute cytotoxic study of the extract was done by Brine shrimp lethality assay and MTT assay by using A549, HeLa, and MCF-7 cancer cell lines were examined. The qualitative analysis of the PDHE extracts evidenced that the immature fruits contain most of the important bioactive principles, which readily accounts for its folklore medicinal claims [18].

Table 1: Phytochemical evaluation of PDHE

\begin{tabular}{ll}
\hline Phytochemicals & Inference \\
\hline Alkaloids & + \\
Glycosides & + \\
Phenolic & + \\
Flavonoids & + \\
Carbohydrates & + \\
Proteins and amino acids & + \\
Terpenoids & + \\
Steroids & + \\
Saponins & + \\
\hline
\end{tabular}

+-indicates the phytochemicals present.

\section{Antioxidant activity}

The antioxidant activity of PDHE extracts was evaluated for its various antioxidant studies like DPPH assay, ABTs assay, and Nitric oxide scavenging assay was carried out. Because a single assay is not satisfactory to evaluate the free radicals scavenging capability of all antioxidants. Since oxidative stress has been implicated in the pathology of many diseases like cancer, the results propose the potential of these plants in the treatment of cancer. Medicinal plants, being the potential source of natural antioxidants, have been widely studied because some synthetic antioxidants are harmful to human health [13]. The scavenging activities have expressed the concentration of an inhibitor where the response is reduced by half $\left(\mathrm{IC}_{50}\right)$. A sample extract with the lowest $\mathrm{IC}_{50}$ value had strong antioxidant activity.

DPPH is a stable free radical that accepts an electron or hydrogen radical to become a stable diamagnetic molecule. The reduction capability of the DPPH radical is determined by the decrease in its absorbance at $516 \mathrm{~nm}$ induced by antioxidants. DPPH assay is one of the most simple and commonly used antioxidant techniques [19] that estimates the capacity of antioxidant compounds to react and scavenge the DPPH free radical [20]. In the studied sample, the $\mathrm{IC}_{50}$ value for DPPH activity was 21.403 and for standard ascorbic acid $16.7741 \mu \mathrm{g} / \mathrm{ml}$ respectively. The results obtained for the extract are excellent when compared with the standard ascorbic acid. The PDHE was the total ethanol extract and not the fractionated one or isolated compound, even showing almost equal activity that of the standard was depicted in table 2. This indicates that the hababuk stage has significant potential to scavenge free radicals [21].

According to previous studies [22], ABTS assay was useful in both organic and inorganic solvent systems to evaluate the antioxidant capacity and was considered a better method compared to DPPH assay. The $\mathrm{IC}_{50}$ value $877.358 \mu \mathrm{g} / \mathrm{ml}$ obtained for the extract and the standard ascorbic acid $189.798 \mu \mathrm{g} / \mathrm{ml}$ respectively, were depicted in table 3 . Further antioxidant capacity was carried out by nitric acid scavenging assay.

Table 2: Antioxidant activity by DPPH assay

\begin{tabular}{llll}
\hline Sample & Sample concentration $(\boldsymbol{\mu g} / \mathbf{m l})$ & Optical density* & \% Inhibition \\
\hline Control & - & 0.9527 & 100 \\
Ascorbic acid (standard) & 12.5 & $0.6040 \pm 0.0105$ & $36.60 \pm 0.0061$ \\
& 25 & $0.2670 \pm 0.0223$ & $71.23 \pm 0.0129$ \\
& 50 & $0.1930 \pm 0.011$ & $78.58 \pm 0.0063$ \\
& 100 & $0.1070 \pm 0.0113$ & $88.24 \pm 0.0066$ \\
Control & 200 & $0.0470 \pm 0.0091$ & $94.85 \pm 0.0053$ \\
PDHE & - & 0.9579 & 100 \\
& 12.5 & $0.7067 \pm 0.0116$ & $25.44 \pm 0.0067$ \\
& 25 & $0.38 \pm 0.0036$ & $59.91 \pm 0.0021$ \\
& 50 & $0.2197 \pm 0.0057$ & $76.82 \pm 0.0033$ \\
& 100 & $0.1794 \pm 0.0011$ & $81.07 \pm 0.0006$ \\
\end{tabular}

*expressed as mean $\pm \mathrm{SD}, \mathrm{n}=3$

Table 3: Antioxidant activity by ABTS assay

\begin{tabular}{llll}
\hline Sample & Sample concentration $(\boldsymbol{\mu g} / \mathbf{m l})$ & Optical density* & \% Inhibition \\
\hline Control & - & 0.9527 & 0.00 \\
Ascorbic acid & 125 & $0.624 \pm 0.0272$ & $35.13 \pm 0.0158$ \\
(standard) & 250 & $0.305 \pm 0.0079$ & $68.29 \pm 0.0046$ \\
& 500 & $0.197 \pm 0.0281$ & $79.52 \pm 0.0163$ \\
& 1000 & $0.097 \pm 0.0121$ & $89.91 \pm 0.0070$ \\
& 2000 & $0.023 \pm 0.0043$ & $97.60 \pm 0.0025$ \\
Control & - & 0.962 & 100 \\
PDHE & 125 & $0.724 \pm 0.0261$ & $24.26 \pm 0.0152$ \\
& 250 & $0.6 \pm 0.0125$ & $37.23 \pm 0.0072$ \\
& 500 & $0.521 \pm 0.02$ & $45.50 \pm 0.0116$ \\
& 1000 & $0.46 \pm 0.0115$ & $51.88 \pm 0.0067$ \\
\end{tabular}

*expressed as mean $\pm \mathrm{SD}, \mathrm{n}=3$ 
The Nitric oxide assay is one of the most extensively utilized methods to determine the antioxidant potential. A potential determination of oxidative damage is the oxidation of tyrosine residue of protein, peroxidation of lipids, and degradation of DNA and oligonucleosomal fragments. Nitric oxide or reactive nitrogen species formed during its reaction with oxygen or with superoxides such as NO2, N204, N304, nitrate, and nitrite are very reactive. These compounds alter the structure and function of many cellular components. Any compound, natural or synthetic, with antioxidant properties might contribute towards the partial or total alleviation of this damage. This assay offers the ability of sample extract to scavenge 452.017 and for the standard gallic acid $140.713 \mu \mathrm{g} / \mathrm{ml}$ [23].

Table 4: Antioxidant activity by Nitric oxide scavenging assay

\begin{tabular}{llll}
\hline Sample & Sample concentration $(\boldsymbol{\mu g} / \mathbf{m l})$ & Optical density $^{*}$ & \% Inhibition \\
\hline Control & - & 0.9527 & 0.00 \\
Gallic Acid (standard) & 125 & $0.05685 \pm 0.0009$ & $33.19 \pm 0.0005$ \\
& 250 & $0.0416 \pm 0.0041$ & $51.11 \pm 0.0024$ \\
& 500 & $0.0203 \pm 0.0017$ & $76.14 \pm 0.0010$ \\
& 1000 & $0.013 \pm 0.0013$ & $84.72 \pm 0.0007$ \\
& 2000 & $0.0049 \pm 0.0007$ & $94.24 \pm 0.0004$ \\
Control & - & & 100 \\
PDHE & 125 & $0.0684 \pm 0.0040$ & $22.53 \pm 0.0023$ \\
& 250 & $0.0578 \pm 0.0043$ & $34.54 \pm 0.0025$ \\
& 500 & $0.041 \pm 0.0072$ & $53.56 \pm 0.0041$ \\
& 1000 & $0.03 \pm 0.0006$ & $66.02 \pm 0.0003$ \\
& $0.0218 \pm 0.0050$ & $75.31 \pm 0.0029$ & \\
\end{tabular}

*expressed as mean $\pm \mathrm{SD}, \mathrm{n}=3$

Table 5: Brine shrimp lethality assay concentration, number of live nauplii, number of dead nauplii, probit value, and LC 50

\begin{tabular}{llll}
\hline $\begin{array}{l}\text { Concentration of PDHE } \\
(\boldsymbol{\mu g} / \mathrm{ml})\end{array}$ & $\begin{array}{l}\text { Number of nauplii } \\
\text { live }\end{array}$ & $\begin{array}{l}\text { Number of nauplii } \\
\text { dead }\end{array}$ & $\begin{array}{l}\text { Observed probit } \\
\text { values }\end{array}$ \\
\hline Control & 9 & 1 & - \\
100 & 8 & 2 & 3.72 \\
200 & 8 & 2 & 3.72 \\
300 & 7 & 3 & 4.16 \\
400 & 6 & 4 & 4.16 \\
500 & 5 & 5 & 4.48 \\
600 & 5 & 5 & 4.75 \\
700 & 4 & 6 & 4.75 \\
800 & 3 & 7 & 5 \\
900 & 2 & 8 & 5.25 \\
1000 & 1 & 9 & 5.84 \\
\hline
\end{tabular}

\section{Acute cytotoxicity by Brine shrimp lethality assay}

The brine shrimp lethality assay represents a rapid, inexpensive and simple bioassay for testing plant extracts bioactivity which in most cases compares practically well with cytotoxic and antitumor properties. In the present study, the brine shrimp lethality of extract PDHE was determined using the procedure of the previous study [24]. The LC50 values of the brine shrimp obtained for extracts and that of the control are given in table-5. Ethanolic extract of PDHE showed the most prominent $\mathrm{LC}_{50}$ values $34.50 \mu \mathrm{g} / \mathrm{ml}$. The degree of lethality was found to be directly proportional to the concentration of the extract. Maximum mortalities took place at a concentration of $1000 \mu \mathrm{g} / \mathrm{ml}$, whereas the least mortalities were at $100 \mu \mathrm{g} / \mathrm{ml}$ concentration compared to that of control. The $\mathrm{LC}_{50}$ values of the plant extracts were obtained by a plot of the percentage of the shrimp nauplii killed against the concentrations of the extracts and the best-fit line was obtained from the data using regression analysis. This significant lethality PDHE extracts to brine shrimp are indicative of the presence of potent cytotoxic components, which warrants further investigation. Fig. 1 illustrates the calculation of dead nauplii against observed probit value.



Fig. 1: The $\mathrm{LC}_{50}$ calculation graph number of dead nauplii against observed probit value 


\section{In vitro cytotoxic activity study by MTT assay}

The antiproliferative study of the PDHE of the Plant Phoenix dactylifera using different cancer cell lines particularly to discover the novel anticancer drugs. MTT assay is an established method of determining the antiproliferative and cytotoxic activity $[25,16]$. The current study investigated the antiproliferative activity of date fruit early-stage hababuk, Phoenix dactylifera, PDHE in A549 (Lung Cancer), HeLa (Cervical cancer) and MCF (Breast Cancer). The methodical evaluation of detailed cytotoxicity cell proliferation effects in human cancer cells revealed that all compounds have dosedependent cytotoxicity cell growth inhibitory activity. The cytotoxicity test performed using MTT assay methods shows a significant reduction of yellow tetrazolium dye to a purple formazan product, as shown in table 6,7 , and 8 . This indicates the ability of the PDHE extract to induce cytotoxicity and decrease cell lethality. Considering the results obtained, it can confirm that the plant contains essential phytochemical constituents and possess active antioxidant and cytotoxic property. However, a majority of the extracts confirmed to be toxic and thus possess anticancer activity.

Table 6: MTT assay of A549 cell lines

\begin{tabular}{llll}
\hline Sample & Sample concentration $(\boldsymbol{\mu g} / \mathbf{m l})$ & 0ptical density* & \% viability $^{*}$ \\
\hline Doxorubicin & 6.25 & $0.3764 \pm 0.0008$ & $59.18 \pm 0.0004$ \\
& 12.5 & $0.2978 \pm 0.0004$ & $67.70 \pm 0.0002$ \\
& 25 & $0.1911 \pm 0.0005$ & $79.25 \pm 0.0003$ \\
& 50 & $0.1445 \pm 0.0019$ & $84.33 \pm 0.0011$ \\
& 100 & $0.1028 \pm 0.0007$ & $88.88 \pm 0.0045$ \\
PDHE & 6.25 & $0.7972 \pm 0.007$ & $6.897 \pm 0.0043$ \\
& 12.5 & $0.7135 \pm 0.006$ & $16.67 \pm 0.0038$ \\
& 25 & $0.6804 \pm 0.008$ & $20.53 \pm 0.0048$ \\
& 50 & $0.6111 \pm 0.007$ & $28.63 \pm 0.0045$ \\
\end{tabular}

*expressed as mean $\pm \mathrm{SD}, \mathrm{n}=3$

Table 7: MTT assay of HeLa cell lines

\begin{tabular}{llll}
\hline Sample & Sample concentration $(\boldsymbol{\mu g} / \mathbf{m l})$ & Optical density $^{*}$ & \% viability $^{*}$ \\
\hline Doxorubicin & 6.25 & $0.477 \pm 0.0065$ & $59.08 \pm 0.0037$ \\
& 12.5 & $0.476 \pm 0.0282$ & $65.54 \pm 0.0164$ \\
& 25 & $0.283 \pm 0.0011$ & $74.07 \pm 0.0006$ \\
& 50 & $0.193 \pm 0.0054$ & $82.32 \pm 0.0031$ \\
PDHE & 100 & $0.163 \pm 0.0008$ & $85.05 \pm 0.0005$ \\
& 6.25 & $1.013 \pm 0.0137$ & $7.34 \pm 0.0079$ \\
& 12.5 & $0.986+0.001$ & $9.78 \pm 0.0005$ \\
& 25 & $0.704 \pm 0.0029$ & $35.53 \pm 0.0017$ \\
\end{tabular}

*expressed as mean $\pm \mathrm{SD}, \mathrm{n}=3$

The selection of the various cell lines like A549 (lung cancer), HeLa (human cervical cancer), and MCF-7 (breast cancer) for our study to identify which cell lines help us to continue our work for the further. The results obtained were 5.27961, 5.28854, and $6.26755 \mu \mathrm{g} / \mathrm{ml}$ for the standard doxorubicin and 139.577, 47.1542, and $68.1826 \mu \mathrm{g} / \mathrm{ml}$ for A549, HeLa, and MCF-7 respectively. Promising results obtained for HeLa cell lines when compared with that of the standard. Our results seem consistent with the correlation previously established between cytotoxicity and brine shrimp lethality in plant extracts. All the activity study results showed the importance of the extract for further development for the anticancer research. This preliminary study given by the cell lines is excellent even though our extract is the total extract and not a fraction or isolated compound. The activity study showed good results confirming the presence of rich phytoconstituents in the hababuk stage of the fruit.

Table 8: MTT Assay of MCF-7 cell lines

\begin{tabular}{llll}
\hline Sample & Sample concentration $(\boldsymbol{\mu g} / \mathbf{m l})$ & Optical density $^{*}$ & \% viability $^{*}$ \\
\hline Doxorubicin & 6.25 & $0.797 \pm 0.0074$ & $6.89 \pm 0.0004$ \\
& 12.5 & $0.713 \pm 0.0065$ & $16.67 \pm 0.0038$ \\
& 25 & $0.680 \pm 0.0083$ & $20.53 \pm 0.0048$ \\
& 50 & $0.611 \pm 0.0078$ & $28.63 \pm 0.0045$ \\
& 100 & $0.54266 \pm 0.0020$ & $36.62 \pm 0.0012$ \\
PDHE & 6.25 & $0.376 \pm 0.0008$ & $59.18 \pm 0.0004$ \\
& 12.5 & $0.297 \pm 0.0004$ & $67.70 \pm 0.0002$ \\
& 25 & $0.1911 \pm 0.0005$ & $79.27 \pm 0.0003$ \\
& 50 & $0.144 \pm 0.0019$ & $84.33 \pm 0.0011$ \\
\end{tabular}

*expressed as mean $\pm \mathrm{SD}, \mathrm{n}=3$

\section{CONCLUSION}

The phytochemical evaluation confirmed the presence of alkaloids, glycosides, phenolic, flavonoids, carbohydrates, proteins, amino acid, terpenoids, steroids, saponins. The antioxidant activity studies DPPH assay, ABTS assay, and nitric oxide also showed excellent results due to the high number of potential constituents. It may be prudent to further explore the hababuk extract for its usefulness in the 
oxidative stress-induced disorders and cancer. Based on the results, it can be concluded that the extract PDHE exhibits varying degrees of cytotoxicity activities against brine shrimp larvae. Finally, the cytotoxicity test performed using MTT assay methods using different cancer cell lines A549, HeLa, and MCF-7, HeLa cell lines showed a significant reduction of yellow tetrazolium dye to a purple formazan product. This indicates the ability of the PDHE extract to induce cytotoxicity and decrease cell viability in cervical cancer.

Considering the results obtained, it can be concluded that the plant contains essential phytochemical constituents and possess active antioxidant and cytotoxic property. Thus, it can be attributed that the presence of these active components can be the basis of the aforesaid properties. Further studies would be required to isolate the bioactive compounds which are responsible for the antioxidant and anticancer activity and determine their underlying molecular mechanism of action to find out novel lead candidates. All the studies were very interesting and recommending in such a manner to continue for our further research work.

\section{ACKNOWLEDGMENT}

All authors extend their gratitude to the Deanship of Scientific Research at Al Qassim University. We are also grateful to the Biogenix Research center, India for doing our activity studies.

\section{FUNDING}

Nil

\section{AUTHORS CONTRIBUTIONS}

All the authors have contributed equally.

\section{CONFLICT OF INTERESTS}

Declared none

\section{REFERENCES}

1. Raina H, Soni G, Jauhari N, Sharma N, Bharadvaja N. Phytochemical importance of medicinal plants as potential sources of anticancer agents. Turkish J Bot 2014;38:1027-35.

2. Shakya AK. Medicinal plants: future source of new drugs. Int J Herb Med 2016;4:59-64.

3. Pradeep A, Dinesh M, Govindraj A, Vinothkumar D, Ramesh Babu N. Phytochemical analysis of some important medicinal plants. Int J Biol Pharm Res 2014;5:48-50.

4. Al-Mamary M, Al-Habori M, Al-Zubairi AS. The in vitro antioxidant activity of different types of palm dates (Phoenix dactylifera) syrups. Arab J Chem 2014;7:964-71.

5. Ali A, Waly M, Essa MM, Devarajan S. Nutritional and medicinal value of date fruit. Dates Prod Process Food Med Values 2014;1:361-71.

6. Abdul Hamid NA, Mustaffer NH, Maulidiani M, Mediani A, Ismail IS, Tham CL, et al. Quality evaluation of the physical properties, phytochemicals, biological activities and proximate analysis of nine Saudi date palm fruit varieties. J Saudi Soc Agric Sci 2020;19:151-60.

7. Hadrami A El, Al-khayri JM. Socioeconomic and traditional importance of date palm. Emirates J Food Agric 2012;24:371-85.

8. Barzin G, Entezari M, Hashemi M, Hajiali S, Ghafoori M, Gholami M. Survey of antimutagenicity and anticancer effect of Phoenix dactylifera pollen grains. Adv Environ Biol 2011;5:3716-8.
9. Sarker SD, Nahar L. Chemistry for pharmacy students: general, organic, and natural product chemistry. John Wiley and Sons Ltd T. editor. Chemistry for Pharmacy Students: General, Organic, and Natural Product Chemistry. British Library Cataloguing in Publication Data; 2013. p. 1-383.

10. CK. Kokate PSBG. Pharmacognosy. $4^{\text {th }}$ ed. Nirali Prakashan; 2010. p. 108-9.

11. Yusuf, Shakkeela KKS. GC-MS analysis of oil isolated and antioxidant activity of shorea robusta oleoresin. Am J Pharm Heal Res 2015;3:1-8.

12. Pappachen LK, Chacko A. In vitro antioxidant activity and determination of total phenolic, flavonoid contents of peperomia pellucida linn. Am J Pharm Heal Res 2013;1:99-101.

13. Noreen H, Semmar N, Farman M, McCullagh JSO. Measurement of total phenolic content and antioxidant activity of aerial parts of medicinal plant coronopus didymus. Asian Pac J Trop Med 2017;10:792-801.

14. Sp D, Raj BA, Muruganantham N, Tk P, Ps R. Screening of wrightia tinctoria leaves for antipsoriatic activity screening of wrightia tinctoria leaves for antipsoriatic activity. J Drugs Med 2012;4:73-8.

15. Lestari MW, Fidrianny I, Yusuf AT, Soemardji AA. Brine shrimp teratogenic screening test on some selected plants. Asian J Pharm Clin Res 2017;10:96-9.

16. Sreejamole KL, Greeshma PM. Antioxidant and brine shrimp cytotoxic activities of ethanolic extract of red alga Cracilaria corticata. J Agardh Indian J Nat Prod Resour 2013;4:233-7.

17. Arung ET, Wicaksono BD, Handoko YA, Kusuma IW, Yulia D, Sandra F. Anti-cancer properties of diethylether extract of wood from Sukun (Artocarpus altilis) in human breast cancer (T47D) cells. Trop J Pharm Res 2009;8:317-24.

18. Zarei O, Yaghoobi MM. Cytotoxic and anti-proliferative effects of Rosa beggeriana Schrenk extracts on human liver and breast cancer cells. Avicenna J Phytomed 2019;9:386-95.

19. Khan F, Ahmed F, Pushparaj PN, Abuzenadah A. Ajwa date (Phoenix dactylifera L.) extract inhibits human breast adenocarcinoma (MCF7) cells in vitro by inducing apoptosis and cell cycle arrest. PLoS One 2016;11:1-17.

20. Umesh Khandekar, Anil Bobade RG. Evaluation of antioxidant activity, in vitro atimicrobial activity and phytoconstituents of schleichera oleosa (lour.) oken. Int J Biol Pharm Res. 2015;6:137-43.

21. SD Sanja, Sheth NR, Patel NK, Patel D, Patel B. Characterization and evaluation of the antioxidant activity of portulaca oleracea. Int J Pharm Pharm Sci 2009;1:74-84.

22. Baskar R, Rajeswari V, Kumar TS. In vitro antioxidant studies in leaves of annona species. Indian J Exp Biol 2007;45:480-5.

23. Chanda S, Dave R. In vitro models for antioxidant activity evaluation and some medicinal plants possessing antioxidant properties: an overview. Afr J Microbiol Res 2009;3:981-96.

24. Ck R, Kl R, Ks J, Joyce GS. Comparative evaluation of antioxidant property in methanol extracts of some common vegetables of India. Sch Res Libr 2011;2:86-94.

25. Krishnaraju AV, Rao TVN, Sundararaju D, Vanisree M. Assessment of bioactivity of Indian medicinal plants using brine shrimp (Artemia salina) Lethality Assay †. Int J Appl Sci Eng 2005;3:125-34.

26. Muruganandam LRM. Anticancer studies of selective mannich bases by in silico method. Int J Curr Pharm Res 2018;10:81. 